University of Wollongong

Research Online

Faculty of Social Sciences - Papers (Archive) Faculty of Arts, Social Sciences \& Humanities

$1-1-2017$

\title{
Childcare Educators' Perceptions of and Solutions to Reducing Sitting Time in Young Children: A Qualitative Study
}

Yvonne Ellis

University of Wollongong, yge019@uowmail.edu.au

Dylan P. Cliff

University of Wollongong, dylanc@uow.edu.au

Anthony D. Okely

University of Wollongong, tokely@uow.edu.au

Follow this and additional works at: https://ro.uow.edu.au/sspapers

Part of the Education Commons, and the Social and Behavioral Sciences Commons

Research Online is the open access institutional repository for the University of Wollongong. For further information contact the UOW Library: research-pubs@uow.edu.au 


\title{
Childcare Educators' Perceptions of and Solutions to Reducing Sitting Time in Young Children: A Qualitative Study
}

\author{
Abstract \\ Young children spend a high proportion of their time at childcare sitting. Reducing sitting time or breaking \\ up prolonged periods of sitting may be positively associated with health outcomes among children. The \\ purpose of this study was to identify childcare educators $i$ perceptions of what environmental and policy \\ modifications could be made within early childhood education and care (ECEC) settings to reduce sitting \\ time among children during childcare. Eighty-seven educators from 11 ECEC centres participated in 11 \\ focus groups between September 2013 and November 2013. Each focus group was audio-recorded and \\ transcribed verbatim. A semi-structured schedule was developed to investigate the educatorsi \\ perceptions of the influences on children $i s$ sitting time at childcare. A problem $i s o l u t i o n$ tree was \\ developed to determine potential solutions for reducing total and prolonged sitting time in young children \\ at childcare. Most educators were unaware of the high levels of sitting time among young children. \\ Educators identified that childcare practices, the physical environment and the weather were factors that \\ influenced children $i s$ sitting time. Potential solutions to reduce sitting time were to break-up prolonged \\ sitting time by using movement breaks, standing desks, movement transitions between activities, \\ relocating key facilities around the space to promote movement, and integrating movement during \\ learning activities. Also, educators suggested that posters could be used to increase awareness among \\ educators about the benefits of reducing sitting time. Educators identified key practices that could be \\ modified to reduce young children $i s$ sitting time in childcare. These potential solutions should be \\ evaluated to understand their effectiveness.
}

\section{Keywords}

time, sitting, reducing, solutions, perceptions, young, educators', study, childcare, children:, qualitative

\section{Disciplines}

Education | Social and Behavioral Sciences

\section{Publication Details}

Ellis, Y. G., Cliff, D. P. \& Okely, A. D. (2017). Childcare Educators' Perceptions of and Solutions to Reducing Sitting Time in Young Children: A Qualitative Study. Early Childhood Education Journal, Online first 1-9. 
Title: Childcare educators' perceptions of and solutions to reducing sitting time in young children: a qualitative study

Short title: Childcare educators’ perceptions on children’s sitting time

Yvonne G. Ellis ${ }^{\mathrm{a}}$, MSc; Dylan P. Cliff ${ }^{\mathrm{a}}$, PhD; Anthony D. Okely ${ }^{\mathrm{a}}$, EdD.

Affiliations: ${ }^{a}$ Early Start, Faculty of Social Sciences, University of Wollongong,

\section{Email addresses:}

Dylan Cliff, PhDª dylanc@uow.edu.au

Anthony D. Okely, EdDª , tokely@uow.edu.au

Address correspondence to: Yvonne Ellis, Early Start Research Institute, Faculty of Social Sciences, University of Wollongong, Wollongong NSW 2522, Australia, [yge019@uowmail.edu.au],+61 242215486

Word count: 3793

Key words: preschool, physical activity, toddlers, sitting, qualitative research 


\section{Abstract}

Young children spend a high proportion of their time at childcare sitting. Reducing sitting time or breaking up prolonged periods of sitting may be positively associated with health outcomes among children. The purpose of this study was to identify childcare educators' perceptions of what environmental and policy modifications could be made within early childhood education and care (ECEC) settings to reduce sitting time among children during childcare. Eighty-seven educators from 11 ECEC centres participated in 11 focus groups between September 2013 and November 2013. Each focus group was audio-recorded and transcribed verbatim. A semi-structured schedule was developed to investigate the educators' perceptions of the influences on children’s sitting time at childcare. A problem-solution tree was developed to determine potential solutions for reducing total and prolonged sitting time in young children at childcare. Most educators were unaware of the high levels of sitting time among young children. Educators identified that childcare practices, the physical environment and the weather were factors that influenced children's sitting time. Potential solutions to reduce sitting time were to break-up prolonged sitting time by using movement breaks, standing desks, movement transitions between activities, relocating key facilities around the space to promote movement, and integrating movement during learning activities. Also, educators suggested that posters could be used to increase awareness among educators about the benefits of reducing sitting time. Educators identified key practices that could be modified to reduce young children's sitting time in childcare. These potential solutions should be evaluated to understand their effectiveness. 


\section{INTRODUCTION}

2 The early years are a critical period of development; it signifies an important period in the establishment of sedentary behaviour (SB) and physical activity (PA) habits for both current and later health (Janz et al. 2005).

$4 \quad$ SB is defined as "any waking activity characterized by an energy expenditure of $\leq 1.5$ metabolic equivalents and a sitting or reclining posture” (p. 540) (Sedentary Behaviour Research Network 2012). Currently, young children spend high proportions 40 to 80\% of their waking time in SB (Colley et al. 2013, Ellis et al. 2016, Reilly 2010, Salmon et al. 2011). Although the evidence appears to be inconsistent (Cliff et al. 2016), some research suggests that, independent of the amount of moderate- to vigorous-intensity physical activity (MVPA) undertaken, prolonged SB may be adversely associated with health outcomes in children, particularly children who are overweight or obese (Cliff et al. 2014, Mitchell et al. 2013, Saunders et al. 2013), which includes 41 million children under the age of 5 worldwide (WHO 2016). Reducing SB (either decreasing overall sitting time or breaking up prolonged sitting) has shown to have a beneficial effect on important markers of cardio-metabolic health in children (Saunders et al. 2013). Internationally, more than $80 \%$ of 3- and 4-year-olds and around one-third of 1- and 2-year-olds spend at least one day a week at childcare (OECD - Organization for Economic Cooperation and Development 2014), and so this setting is important in shaping children's sedentary habits (Ward et al. 2010). Therefore, childcare is being positioned as a potential system for intervention in a general public health problem. Sedentary behaviour recommendations have been developed for children at childcare (Institute of Medicine 2011). These recommend that young children should be allowed to move freely and that sitting or standing still should be limited to 30 minutes at a time (Institute of Medicine 2011). A recent study in 11 childcare settings in Australia showed that nearly half of the preschoolers and one third of the toddlers in childcare did not meet this recommendation and that they spent approximately 50\% of their childcare day sitting (Ellis et al. 2016). As such, it is important to identify why children spend high proportions of time sitting in childcare settings and what can be done to reduce this. A recent systematic review of quantitative studies investigating the correlates of children's sedentary behaviour in childcare settings found that the most significant influence was the physical environment (Tonge et al. 2016).

There are limited qualitative studies examining educators' perspectives of the factors that may influence sitting time in childcare centres (De Decker et al. 2013, Määttä et al. 2016). In this setting, childcare educators’ have an important role in shaping children's SB, as they are partly responsible for the policies, practices and environments at childcare. Identifying childcare educator's perceptions of the potential solutions for reducing 
31 children's sitting time is important as it may result in the development of effective and solution-oriented interventions for decreasing sitting time among young children (De Decker et al. 2013, Robinson and Sirard 2005).

The aim of this study was to understand early childhood educators' perceptions of young children's sitting time in childcare, the potential factors that contribute to high levels of sitting and potential modifications that could be made within childcare centres to reduce total and prolonged sitting among children during childcare.

Specifically, the following research questions were addressed:

1. What are educators' perceptions of the amount of time children spend sitting in childcare centres? centres?

\section{METHODS}

\section{Participants}

48 Using community-based participatory research methods (Israel et al. 2001), this qualitative study involved focus groups with educators, from 11 childcare centres within the Illawarra and Shoalhaven regions of NSW, Australia (population. 0.4 million). All directors from these childcare centres agreed to run a focus group. Focus groups with childcare directors, educators and central administration staff were held in each childcare centre during staff meetings and took place over a three-month period (August-October, 2013) as part of the Standing Preschool Study (Ellis et al. 2016). This study focused on young children's sitting time at childcare and how to break up prolonged sitting.

Five of the 11 centres were located in middle socio-economic status (SES) suburbs and six in low SES suburbs. The SES status of the centre suburb was based on the 2011 Socio-Economic Indices for Areas (SEIFA) Index of Relative Socio-Economic Disadvantage (Australian Bureau of Statistics 2011). If the score of a suburb was located below the fourth decile, it was categorized as low SES, otherwise middle SES. This study received approval by the Human Research Ethics Committee at the University of Wollongong (HE13/406). 


\section{Data collection}

62 Two female researchers facilitated all 11 focus groups. Each educator was asked to complete written informed 63 consent prior to the focus groups. Focus groups lasted between 40 and 60 minutes (mean $=50.11 \mathrm{~min}$ ). Each of 64 the focus groups was audio-recorded and transcribed verbatim. In addition, key points, which were not captured on tape, such as body language, were written down at the time by the researcher to capture important contextual information from the focus groups.

A semi-structured schedule was developed based on the problem-and solution tree tool (Snowdon et al. 2008) to examine the educator's perceptions of the causes of and potential solutions for modifying young children's high sitting time in childcare. The problem-and-solution tree tool has successfully been used in health research (Snowdon et al. 2008). At the beginning of each focus group for each centre, children's sitting, standing and stepping time data from phase I of the Standing Preschool Study were reported back to the specific centre (Ellis et al. 2016). Each focus group then worked their way through the following steps as per the problem and solution tree approach: 1) reached agreement that current rates of total and prolonged sitting their childcare centre were too high; 2) identified factors (e.g. policy, physical and social environment) that contributed to this problem; 3) brainstormed solutions (positives) to the causes of the factors identified in Step 2 (negatives); 4) prioritised the identified solutions based on feasibility and acceptability; and 5) included any "floating” solutions not linked to a specific problem factor but considered by the group to be important.

\section{Data management and analyses}

The digital audio files from each focus group discussion were transcribed verbatim. Data analysis followed by the guidelines for thematic analysis outlined by Braun and Clarke (2006). To enhance trustworthiness of the analysis a "critical friend", a colleague who was not involved in the project, was used to provide feedback on the process of the analysis (Sparkes and Smith 2014). The lead author read and listened to the audio recording to become familiarised with the data. Each transcript was then coded thematically; this was an open coding process, whereby meaningful quotes or key examples from educators were assigned a code. These "emergent" codes were then grouped together to develop themes (Braun and Clarke 2006). Once themes were developed, the second and third author provided critical feedback on the analysis and interpretations of the study. The peer debrief was concerned with the on-going process of data collection and analysis. This process took place through regular meetings between the research team. 


\section{RESULTS}

92 A total of 87 childcare educators participated in the study and each focus group had between 3 and 10

93 participants, of which 99\% were female.

94

Step 1: What are educators' perceptions of the amount of time children spend sitting in childcare centres?

96

97

98

99

100

101

102

103

104

105

106

107

108

109

110

111

112

113

114

115

116

117

118

Insert Table 1 around here

\subsection{Lack of awareness}

\subsection{Acknowledgement of findings} children's sitting time (1.2.3). centres? (Table 2)

8 reported back to educators from that centre. The educators gave their initial perceptions on the amount of time spent sitting in their childcare centre.

The majority of educators were surprised that around half of children's time at childcare was spent sitting, as the common perception was that children were considerably active throughout the day (1.1.1, 1.1.2). Furthermore, educators were also not aware of the benefits for children of standing and spending more time in light-intensity physical activity, or the potential consequences of prolonged bouts of sitting (1.1.3).

The educators generally accepted the findings that girls spent more time sitting than boys (1.2.1) and that preschoolers would sit for longer periods of time compared to toddlers, as preschoolers tended to find something to do and sit down to do it (1.2.2). All educators agreed to consider potential solutions to reduce young

\section{9}

$120 \quad 2.1$ Childcare practices

Step 2: According to educators, what factors may contribute to children's sitting time in childcare

The next step was to identify any factors that would contribute to high sitting time. Educators identified that the childcare routine, physical environment, parent and educator values were the strongest factors. 
121 When considering the factors that may contribute to high levels of sitting among children in childcare, childcare

122 practices was the most common theme identified by educators. Some educators mentioned that prolonged

123 periods of sitting occur especially during the morning activities, and that there is a need to try and break this up.

124 Moreover, one educator highlighted that in the early afternoon period there were activities in which sitting

125 occurred for longer lengths of time (2.1.1). Another activity, which is often a part of the morning and afternoon

126 routine, is story time. Educators recognized this as an activity in which children would remain seated throughout

127 its duration (2.1.1). Group time, which typically involves gathering the children to share learning experiences,

128 was also mentioned by most educators as one of the times in their daily routine where a lot of sitting occurred

129 (2.1.2). During rest or nap time, educators reported that children were mainly involved in quiet sitting activities,

130 such as puzzles, or drawing sitting down at a table (2.1.3) if they were not napping. Some educators suggested

131 that compared with toddlers, preschoolers tended to have higher concentration levels and this was a reason why

132 they spent longer lengths of time sitting down (2.1.3). In addition, educators mentioned that during social times,

133 such as mealtimes, children were required to sit (2.1.4).

134

1352.2 Physical and natural environment

136 The physical environment was noted by several educators as one of the key factors influencing high levels of

137 sitting, specifically the lack of adequate outdoor space (2.2.1). Another natural environmental factor discussed

138 by the educators was bad weather along with shorter days during winter, both of which they felt acted to limit

139 children’s physical activity outside and increased sitting time indoors. Moreover, educators indicated that the

140 difference between summer (daylight savings) and winter routines could have an influence on children's sitting

141 time, as the length of time children spent outside was longer during the summer routine (2.2.2, 2.2.3, 2.2.4).

142

1432.3 Parental and educator values

144 Educators stated that parents' values and expectations influenced the activities completed at childcare, which

145 may subsequently influence children's sitting time. First, educators perceived that parents want their child to rest,

146 which usually involves sitting or lying down (2.3.1). Secondly, educators perceived that children’s "school

147 readiness" was an area that was highly salient for parents. According to educators, parents want their children to

148 "be ready" for school, and therefore felt that children needed to learn to sit at a table at an early age (2.3.2).

149 Likewise, some educators reported they wanted the children ready for school (2.3.3). A common view by 
educators was that concentrating requires sitting, and therefore group time usually included sitting. Furthermore,

151 educators expressed that sitting is often used as a boundary, highlighting that it calms children down (2.3.4).

Insert table 2 around here

Step 3: According to educators, what are the potential solutions to reducing children's sitting time in childcare centres? (Table 3)

157 Solutions to reducing total and prolonged sitting in children at childcare were suggested by educators in the

158 following themes: 3.1 childcare practice changes, 3.2 physical environment changes, 3.3 additional equipment, 159 and 3.4 awareness.

\subsection{Childcare practice changes}

162 Educators suggested modifications to current routine activities that may reduce children's sitting time in 163 childcare. They mentioned certain practices where sitting is not really required. For example, a song several 164 educators use during their daily practices, is "look who is here now", which is often done sitting down, but could 165 easily be changed to getting the child to stand up when they hear their name (3.1.1). Changing the order of 166 activities within the childcare routine would be another possibility to break up prolonged sitting (3.1.2).

167 Modifying the place where children have lunch was suggested as another option (3.1.3). During lunch, most 168 centres have a bin in the middle of the table to place rubbish in. Educators suggested that instead of having the 169 bin in the middle of the table it could be placed further away, meaning that children would need to stand up and 170 walk to the bin (3.1.4). As children often sit for prolonged periods of time during mealtime, educators reported 171 they could possibly do a movement break after the meal (3.1.5). To break up sitting time during story time, 172 educators all suggested that they could ask children to stand up and come over to the educator to turn the page 173 (3.1.6).

\subsection{Physical environment changes}

176 Within the physical environment, educators identified several changes that could be easily implemented to 177 reduce sitting time. The majority reported that moving the chairs away from the tables would be a potential 178 solution to reduce sitting time (3.2.1), but highlighted that they still want to have the some experiences at the 179 tables (3.2.2). When taking away chairs from some tables, educators mentioned that it was important to rotate 
the activities, because then different children would be targeted (3.2.3). In one childcare centre, educators

181 reported that they had implemented this strategy after data on children's sitting time was collected during phase I

182 of this study (3.2.4). Educators indicated that it was also important for them to consider where activities were

183 located before mealtimes. In one centre where they had two outdoor spaces, children tended to move more and

184 sit less when group time took place in the larger space, compared to the smaller space (3.2.5).

185

186

\subsection{Equipment}

187 Educators mentioned numerous types of equipment that could reduce sitting time among children in childcare.

188 Having more easels was one suggestion, as these encourage children to stand when painting or drawing (3.3.1).

189 Mini trampolines were suggested as another solution as this equipment does not take up a lot of space and it is a

190 quick way for children to be energetically active (3.3.2). Children in childcare have the possibility of spending

191 some time on electronic tablets and this is typically completed sitting down. The educators suggested that a

192 standing table where children could use an electronic tablet would be one way to decrease time spent sitting

193 (3.3.3). Lastly, educators identified that wall-mounted activities, such as puzzles or a water wall, would be

194 another possible modification to reduce sitting time (3.3.4, 3.3.5).

195

1963.4 Awareness

197 In addition to having practical solutions, educators highlighted that it may also be important for them to be more

198 aware of the time children spent sitting while in childcare and developing habits to reflect on implementing the

199 proposed changes to reduce sitting time (3.4.1, 3.4.2,). Likewise, educators also mentioned that the mind-set of

200 children should be encouraged when implementing changes in the physical environment (3.4.3), as some

201 children were not sure if they could still use a certain space when the equipment or furniture has changes. This

202 would be better supported if parents were also more aware of why children need to break up their sitting time

203 (3.4.4). Most educators agreed that the activities should be realistic and used consistently (3.4.5,). According to

204 one educator, the key to implement the activities is to make it visual (putting up a sign in the room) for other

205 educators (3.4.6).

206

207 
Table 1. Quotations from educators for Step1: What are the educator's perceptions on young children's sitting time?

\begin{tabular}{|l|l|}
\hline $\mathbf{1 . 1}$ & Lack of awareness \\
\hline 1.1 .1 & Yes, I am surprised with the results, it is a surprise. Because we do think they do so much moving throughout the day \\
\hline 1.1 .2 & 60\% at first, I thought wow, it would be good to get it down a little. \\
\hline 1.1 .3 & I just didn't know if we were benefitting the children when we do remove the chairs and standing how, you know, is benefitting them \\
\hline $\mathbf{1 . 2}$ & Acknowledgements of findings \\
\hline 1.2 .1 & $\begin{array}{l}\text { It wouldn't surprise me yeah, they are more into their drawings, painting and craft sort of things yeah. While the boys would rather be outside } \\
\text { kicking the ball. }\end{array}$ \\
\hline 1.2 .2 & I sort of can see when the babies don't sit as much as the pre-schoolers, because the pre-schoolers will find something to do and sit down. \\
\hline 1.2 .3 & I would love to see 35\% sitting time, because they will do enough sitting when they get to school. \\
\hline
\end{tabular}

Table 2. Quotations from educators for Step 2: Which factors did educators identify that contributed to high sitting time?

\begin{tabular}{|c|c|}
\hline 2.1 & Childcare practices \\
\hline 2.1 .1 & $\begin{array}{l}\text { They also get to scrape all their fruit. So they can pour their own drinks. Sit down lunch is served and they eat their lunch. And then they go up } \\
\text { and scrape their bowl, and then they will come sit back down for fruit. When they done that they'll go straight to story and sit down. And from } \\
\text { there they then do storytime and relaxation and they do quiet activities which is generally always at the table. - Predominantly sitting down }\end{array}$ \\
\hline 2.1 .2 & Group time is where a lot of sitting times comes from \\
\hline 2.1 .3 & $\begin{array}{l}\text { They can spend rest time for an hour in one area; it can be here at the writing centre, creating and making or moulding things, or at a game table } \\
\text { or puzzle table. Their concentration has expanded and they spend a long length of time sitting down }\end{array}$ \\
\hline 2.1 .4 & Like in the mealtime, so that is morning tea, lunch and afternoon tea, they are all sitting times. They need to be sitting times. \\
\hline 2.2 & Physical and natural environment \\
\hline 2.2 .1 & But I do think the problem is the lack of space, because when you get these kids that are full on. \\
\hline 2.2 .2 & Like we said being into our summer routine we are in the yard earlier in the morning. Longer time out there to run around to play. \\
\hline 2.2 .3 & $\begin{array}{l}\text { Because daylight savings, we cant be outside in the middle of the day. I guess there is more room to move outside, which means they might be } \\
\text { more active. }\end{array}$ \\
\hline 2.2 .4 & $\begin{array}{l}\text { This afternoon too, now that it is getting warmer the kids are getting so much more involved in the gardening and the watering and walking } \\
\text { around so its weather conditions connected as well }\end{array}$ \\
\hline 2.3 & Parent and educator values \\
\hline 2.3 .1 & $\begin{array}{l}\text { And I guess the other one too like the rest and relaxation would be a big one where they probably be sitting a lot, but we have tried to start } \\
\text { incorporating Thai chi and yoga and more of those sort of things. But on the flipside of that too parents do want their children to rest. }\end{array}$ \\
\hline 2.3 .2 & $\begin{array}{l}\text { I guess its finding a balance between the cus half especially for the preschool routine we get a lot of our parents want them to get ready for } \\
\text { school, like, so and they do have to sit at a table and concentrate at times at school so that's what the focus group sometimes tend to be, } \\
\text { especially the morning ones. So I think that it would be quite difficult to get away from that" }\end{array}$ \\
\hline 2.3 .3 & I was just thinking of the older ones, because of school readiness, you got to get them ready to sit. Its about proper preparation and transition \\
\hline
\end{tabular}




\begin{tabular}{|l|l|}
\hline & too. \\
\hline 2.3 .4 & $\begin{array}{l}\text { Often we tell children when we gathering them for a transition over here or to wash hands, we are getting them to sit down, and some of them } \\
\text { need some boundaries and that's why sitting calms them. But if we had something like a circle or dot they can stand on. Its still a boundary }\end{array}$ \\
\hline
\end{tabular}

Table 3. Quotations from educators for step 3: Which solutions did the educators identify to reduce sitting time?

\begin{tabular}{|c|c|}
\hline 3.1 & Childcare practices changes \\
\hline 3.1 .1 & $\begin{array}{l}\text { Or with "look who is here now", it is good to see Emily is here and they can stand up. Or just even standing up and then sitting down makes } \\
\text { a difference. And that is easy to do. We sing it every day! }\end{array}$ \\
\hline 3.1 .2 & $\begin{array}{l}\text { We reflected on that as well and we were doing that where they } 10.30 \text { they were doing indoor/outdoor in this room but now they come in } \\
\text { for a bit of sitting, and then its news and then its free play inside, news, group in door outdoor and then lunch. We mixed it up a bit, it's too } \\
\text { much sitting sitting. }\end{array}$ \\
\hline 3.1 .3 & $\begin{array}{l}\text { I mean mealtimes you've got no choice, Legally they have to be you know they can chocke bla bla bla. But we had a picnic, now that's } \\
\text { different, you have to reach right over to put something in the bin, you have to get right up to you know...they like that. }\end{array}$ \\
\hline 3.1 .4 & $\begin{array}{l}\text { We could trial not have the bin on the table, but move the bin, so they have to walk to put the rubbish in the bin. Like a separate table with } \\
\text { the bin. }\end{array}$ \\
\hline 3.1 .5 & Include energy breaks after meal times as meal times involve a long sitting period. \\
\hline 3.1 .6 & $\begin{array}{l}\text { I remember when I was in preschool, we had a big book and the teacher would let you come up and turn the page. You know, its not all of } \\
\text { them, but if you sitting nicely you can come up and turn the page next }\end{array}$ \\
\hline 3.2 & Physical environment changes \\
\hline 3.2 .1 & Simply moving the chairs away from the tables. \\
\hline 3.2 .2 & $\begin{array}{l}\text { Well I guess what you said, we can do more things like not having the chairs at the tables, with experiences, because you still want those } \\
\text { experiences set up. Like you still want to have things like drawing out. }\end{array}$ \\
\hline 3.2 .3 & $\begin{array}{l}\text { Some children might always do creative arts. If you got chairs missing from the creative area it will benefit those children. But if you take } \\
\text { chairs away from the puzzle area, then you will target different children. }\end{array}$ \\
\hline 3.2 .4 & $\begin{array}{l}\text { The other thing we have got now is the train table. Instead of having it at the floor, they do that constantly, they are always standing at that } \\
\text { table. They didn't have that before when you did the study. }\end{array}$ \\
\hline 3.2 .5 & $\begin{array}{l}\text { Even before lunch, we did like our group time in the big yard. And that changed so much on how they move, because there is so much more } \\
\text { space. }\end{array}$ \\
\hline 3.3 & Equipment \\
\hline 3.3 .1 & $\begin{array}{l}\text { Yeah just rethinking, do we get a few more easels, because art can be, you tend to stand more when you are at an easel. Its one way of } \\
\text { looking at it. It does encourage that. If you got an easel with two sides, it would encourage more. }\end{array}$ \\
\hline 3.3 .2 & $\begin{array}{l}\text { I have suggested on getting mini trampolines, so then if you feel like there is a need to get rid of some energy we could use those. For like a } \\
\text { sensory as well as energy. And it doesn't take up a lot of space and it is in the one spot. With some of the behaviours sometimes you know }\end{array}$ \\
\hline
\end{tabular}


you are struggling with the height and behaviours, they need to be recentered. It's a outlet.

\begin{tabular}{|l|l|}
\hline & you are struggling with the height and behaviours, they need to be recentered. It's a outlet. \\
\hline 3.3 .3 & $\begin{array}{l}\text { I wonder with the iPad, because that's a time where they are sitting usually. We usually try to get them to stretch or do something after it. } \\
\text { But if you had the table they can be standing at the height. And it is safe for the iPad as well. }\end{array}$ \\
\hline 3.3 .4 & Puzzle mounted at the wall by strings. \\
\hline 3.3 .5 & We are constructing a water wall with constructed water bottles. \\
\hline 3.4 & Awareness \\
\hline 3.4 .1 & $\begin{array}{l}\text { And that's just getting it in your mind, sometimes I walk past and experience oh maybe I should have put the chairs away too, } \\
\text { because they got paint all over them all they have done is stood there with the chair behind them anyway. That is one thing we can } \\
\text { get more in the habit of doing. }\end{array}$ \\
\hline 3.4 .2 & $\begin{array}{l}\text { So, these are all ideas that we all had and all been trained in, it is just about rethinking and re-implementing and basically thinking a } \\
\text { bit more why we are doing this. }\end{array}$ \\
\hline 3.4 .3 & $\begin{array}{l}\text { I think its about encouraging the children's mind-set, even though they are very young. Because when we did take the tables away first time } \\
\text { they assumed the area was closed. }\end{array}$ \\
\hline 3.4 .4 & $\begin{array}{l}\text { What I like to do is let the parents know and give them a reason why it is really good for children, do you have anything as far as research } \\
\text { shows I know that some children need to centre, but is the way to centre them to give them some physical release and then they can centre } \\
\text { and then they can focus, do you have anything that might explain that. }\end{array}$ \\
\hline 3.4 .5 & $\begin{array}{l}\text { Remembering to implement and sustain the changes suggested. } \\
\text { For us I think it is about looking at how we would predominantly learn, a visual thing. Putting something up on the wall, remembering how } \\
\text { to do this. And talking about it during staff meetings, so everybody is on board at doing similar things. Making sure the staff are doing what } \\
\text { we ask them to do. And that is the biggest thing I think around this, it needs to become automatic without thinking about it all the time. }\end{array}$ \\
\hline 3.4 .6 &
\end{tabular}




\section{Discussion}

210 The purpose of this qualitative study was to understand early childhood educators' perceptions of young

211 children's sitting time in childcare, potential factors that contribute to high levels of sitting time, and possible

212 modifications that could be made within childcare centres to promote less sitting among children. Thematic

213 analysis of focus group data showed that most educators were surprised that children spent approximately 50\%

214 of their day sitting in childcare (Ellis et al. 2016), and that they generally agreed this could be reduced by

215 identifying factors that contributed to high levels of sitting among children, and developing potential solutions to

216 reduce children's sitting. The factors included childcare practices, physical and natural environment, as well as

217 parent and educator values. The potential solutions that educators identified included changes in childcare

218 practice, the physical environment and equipment to reduce sitting time. To implement these changes, educators emphasised being more mindful about this through reminding educators and children, being consistent and providing information sessions with educators and parents. These findings could be used to inform the development of interventions to reduce sitting time in childcare.

The first important finding was that the majority of educators were surprised that children spent a large proportion of their time in childcare sitting; they believed that young children engaged in a lot of moving

224 throughout the day. This finding is in line with other qualitative studies (De Decker et al. 2013, Määttä et al. 2016), where educators assumed that preschoolers engage in adequate PA behaviours during childcare. These

226 educator perceptions do not correspond with recent research based on objective measurements, indicating that young children spend $40 \%$ to $80 \%$ of their day at childcare in SB (Ellis et al. 2016, Brown et al. 2009). This could be due to a lack of awareness or knowledge of recent research, and not knowing the guidelines for young children's SB or PA. So providing educators with information about the prevalence of young children's sitting time in childcare, as well as SB and PA guidelines might be important when developing interventions to reduce 231 sitting time.

The second important finding that warrants discussion is the educators' perceptions of the factors that

233 influence children's sitting time in childcare. In this study, educators mentioned that children mostly sat during

234 group sessions, such as mealtimes and group times, which is consistent with findings from other studies (De

235 Decker et al. 2013, Määtä et al. 2016). In addition, educators identified that the physical environment was a 236 potential factor influencing children's sitting time. Moreover, educators reported that the weather and season 237 might influence children’s sitting time. Interestingly, studies by O’Connor and Temple (2005) and De Decker et 
al. (2013) somewhat support this finding; they noted that the weather also had an important influence on physical activity levels in children at family daycare and childcare. Given the potential increase in children’s sitting time

240 due to bad weather conditions, it is important for childcare centres to provide creative solutions to counter the 241 impact of these environmental limitations.

242 According to educators, parental and educator values also play an important role in the amount of time

243 children spent sitting, as they both have a strong belief that children are required to learn to sit still to be ready to

244 go to school. This finding is consistent with two studies where educators report that children need to sit down to 245 be prepared for primary school (De Decker et al. 2013, Määttä et al. 2016). They furthermore reported that 246 sitting assists in calming children, and that it is often used as a boundary. Additionally, their view was that 247 children need to sit down to concentrate. However, Diamond \& Lee (2011) reported that higher order cognitive 248 processes such as executive functions, which are a better predictor of school readiness than IQ (Blair and Razza 249 2007, Welsh et al. 2010), could be improved through not requiring the children to sit still for long periods of 250 time (Diamond and Lee 2011). Therefore, educating parents and educators on the importance of providing children with different ways of learning that integrate movement and limit prolonged sitting might be necessary. Lastly, changes in the childcare practice, physical environment and the educator awareness were suggested as potential solutions to reduce sitting time in young children, a finding that is in line with De Decker 254 et al. (2013). However in the focus groups in the study of De Decker (2013) not all topics were addressed that 255 could potentially influence preschooler's sedentariness (e.g., presence of desks in the classroom, incorporating 256 standing or light physical activity into otherwise sedentary lessons). Whereas in this study the educators 257 suggested removing chairs or implementing a standing desk, which has been shown to decrease overall 258 sedentariness in primary school children (Hinckson et al. 2013). Plus a further benefit is that the tables in 259 childcare are often an ideal height for a standing table, meaning that it will be simple to implement in all the 260 childcare centres. Also movement breaks after long periods of time sitting were suggested by the educators.

261 Including breaks has been shown to be an effective option to increase physical activity levels in children (Katz et 262 al. 2010), however, to our knowledge, the effects of activity breaks in preschool children during childcare have 263 not yet been investigated.

264 This is the first study in Australia to explore the educators' perceptions of the factors that influence 265 children's sitting time in childcare centres and potential solutions to reduce this. Further strengths of the current 266 study include the use of focus groups to explore childcare educators' ideas about realistic, practical, acceptable, 267 and sustainable solutions that can be used in reducing sitting in their daily practice. Their proposed solutions 
express awareness of the need for healthy practices. Lastly, the semi-structured schedule allowed childcare educators to discuss themes and generate new solutions that the moderator had not thought of before the focus group. However, limitations include the use of focus groups where educators may have felt peer pressure to provide similar answers as their colleagues or "acceptable" responses to the facilitator. Furthermore, at the time

272 no demographic descriptives were obtained from the educators, which is important information for interpreting 273 the results.

\section{Implications}

276 This study confirms that engaging childcare educators in sharing their perceptions and ideas is an important first step to creating and implementing an intervention to reduce sitting time in young children. Furthermore, childcare educators should receive workshops or course material on how to reduce sedentary behaviour and promote physical activity at childcare.

\section{Conclusion}

283 In conclusion, this qualitative study shows that childcare educators are unaware of the current levels of sitting

284 time in young children at childcare. Educators identified the childcare practice physical environment and parental and educators' values as factors that could be modified to reduce young children's sitting time in childcare. These potential solutions should be evaluated to understand their effectiveness.

\section{Key messages}

Interventions to reduce sitting time in young children at childcare, should:

- Increase educators awareness by providing training for childcare educators and parents on implementing new strategies to reduce sitting time - $\quad$ Modify childcare practice sitting activities with standing or movement breaks.

\section{Funding}

297 This research was supported by a faculty grant by the University of Wollongong. Cliff was funded by an 
Australian Research Council (ARC) Discovery Early Career Researcher Award (DE140101588). The funders of the study had no role in the design and conduct of the study: collection, management, analysis, or interpretation of the data: preparation, review, or approval of the manuscript: and decision to submit for publication.

\section{Acknowledgments}

We thank the participating educators from the childcare centres located in the Illawarra region and Tamara Raso (project manager).

\section{Conflict of interest}

The authors declare they have no competing interests

\section{References}

Australian Bureau of Statistics (2011) Census of Population and Housing: SocioEconomic Indexes for Areas (SEIFA) 2033.055.001. . Australian Bureau of Statistics, Canberra.

Blair, C. \& Razza, R. P. (2007) Relating effortful control, executive function, and false belief understanding to emerging math and literacy ability in kindergarten. Child development, 78, 647-663.

Braun, V. \& Clarke, V. (2006) Using thematic analysis in psychology. Qualitative research in psychology, 3, 77-101.

Brown, W. H., Pfeiffer, K. A., Mciver, K. L., Dowda, M., Addy, C. L. \& Pate, R. R. (2009) Social and environmental factors associated with preschoolers, Äô nonsedentary physical activity. Child development, 80, 45-58.

Cliff, D. P., Hesketh, K., Vella, S. A., Hinkley, T., Tsiros, M. D., Ridgers, N. D., Carver, A., Veitch, J., Parrish, A. M. \& Hardy, L. L. (2016) Objectively measured sedentary behaviour and health and development in children and adolescents: systematic review and meta - analysis. Obesity Reviews.

Cliff, D. P., Jones, R. A., Burrows, T. L., Morgan, P. J., Collins, C. E., Baur, L. A. \& Okely, A. D. (2014) Volumes and bouts of sedentary behavior and physical activity: associations with cardiometabolic health in obese children. Obesity, 22, E112E118.

Colley, R. C., Garriguet, D., Adamo, K. B., Carson, V., Janssen, I., Timmons, B. W. \& Tremblay, M. S. (2013) Physical activity and sedentary behavior during the early years in Canada: a cross-sectional study. International Journal of Behavioral Nutrition and Physical Activity, 10, 54.

De Decker, E., De Craemer, M., De Bourdeaudhuij, I., Wijndaele, K., Duvinage, K., Androutsos, O., Iotova, V., Lateva, M., Alvira, J. M. F. \& Zych, K. (2013) Influencing factors of sedentary behavior in European preschool settings: an exploration through focus groups with teachers. Journal of school health, 83, 654-661. 
Diamond, A. \& Lee, K. (2011) Interventions shown to aid executive function development in children 4 to 12 years old. Science, 333, 959-964.

Ellis, Y. G., Cliff, D. P., Janssen, X., Jones, R. A., Reilly, J. J. \& Okely, A. D. (2016) Sedentary Time, Physical Activity and Compliance with IOM Recommendations in Young Children at Childcare. Preventive Medicine Reports.

Hinckson, E. A., Aminian, S., Ikeda, E., Stewart, T., Oliver, M., Duncan, S. \& Schofield, G. (2013) Acceptability of standing workstations in elementary schools: a pilot study. Preventive medicine, 56, 82-85.

Institute of Medicine. (2011) Early Childhood Obesity Prevention Policies From Institute Of Medicine. Available at: http://iom.edu/Reports/2011/Early-ChildhoodObesity-Prevention-Policies/Recommendations.aspx (2015 Feb 2 2015)

Israel, B. A., Schulz, A. J., Parker, E. A. \& Becker, A. B. (2001) Community-based participatory research: policy recommendations for promoting a partnership approach in health research. Education for health, 14, 182-197.

Janz, K. F., Burns, T. L. \& Levy, S. M. (2005) Tracking of activity and sedentary behaviors in childhood: the Iowa Bone Development Study. American journal of preventive medicine, 29, 171-178.

Katz, D. L., Cushman, D., Reynolds, J., Njike, V., Treu, J. A., Katz, C., Walker, J. \& Smith, E. (2010) Peer reviewed: Putting physical activity where it fits in the school day: Preliminary results of the ABC (Activity Bursts in the Classroom) for fitness program. Preventing chronic disease, 7.

Määttä, S., Ray, C., Roos, G. \& Roos, E. (2016) Applying a socioecological model to understand preschool children's sedentary behaviors from the viewpoints of parents and preschool personnel. Early Childhood Education Journal, 44, 491-502.

Mitchell, J., Pate, R., Beets, M. \& Nader, P. (2013) Time spent in sedentary behavior and changes in childhood BMI: a longitudinal study from ages 9 to 15 years. International journal of obesity, 37, 54-60.

Oecd - Organization for Economic Cooperation and Development, F. D. (2014) PF3.2: Enrolment in Childcare and Pre-Schools. Directorate of Employment, Labour and Social Affairs

Reilly, J. J. (2010) Low levels of objectively measured physical activity in preschoolers in child care. Medicine and science in sports and exercise, 42, 502-507.

Robinson, T. N. \& Sirard, J. R. (2005) Preventing childhood obesity: a solution-oriented research paradigm. American journal of preventive medicine, 28, 194-201.

Salmon, J., Tremblay, M. S., Marshall, S. J. \& Hume, C. (2011) Health risks, correlates, and interventions to reduce sedentary behavior in young people. Am J Prev Med, 41, 197-206.

Saunders, T. J., Tremblay, M. S., Mathieu, M.-È., Henderson, M., O’loughlin, J., Tremblay, A., Chaput, J.-P. \& Group, Q. C. R. (2013) Associations of sedentary behavior, sedentary bouts and breaks in sedentary time with cardiometabolic risk in children with a family history of obesity.PLoS One 8, 11, e79143

Sedentary Behaviour Research Network (2012) Standardized use of the terms "sedentary" and "sedentary behaviours". Appl Physiol Nutr Metab., 37, 540-542.

Snowdon, W., Schultz, J. \& Swinburn, B. (2008) Problem and solution trees: a practical approach for identifying potential interventions to improve population nutrition. Health promotion international, 23, 345-353.

Sparkes, A. C. \& Smith, B. (2014) Qualitative Research Methods in Sport, Exercise and Health: from Product to Process, Routledge, London. 
Tonge, K. L., Jones, R. A. \& Okely, A. D. (2016) Correlates of children's objectively measured physical activity and sedentary behavior in early childhood education and care services: A systematic review. Preventive medicine, 89, 129-139.

Ward, D. S., Vaughn, A., Mcwilliams, C. \& Hales, D. (2010) Interventions for increasing physical activity at child care. Medicine and science in sports and exercise, 42, 526534.

Welsh, J. A., Nix, R. L., Blair, C., Bierman, K. L. \& Nelson, K. E. (2010) The development of cognitive skills and gains in academic school readiness for children from lowincome families. Journal of educational psychology, 102, 43.

Who (2016) Commission's final report calls for high-level action to address major health challenge In: Commission on Ending Childhood Obesity Geneva. 